\title{
Intra-tumoral treatment with oxygen-ozone in glioblastoma: A systematic literature search and results of a case series
}

\author{
RICHARD MEGELE ${ }^{1}$, MARKUS J. RIEMENSCHNEIDER ${ }^{2}$, FRANK DODOO-SCHITTKO ${ }^{3}$, \\ MATTHIAS FEYRER $^{4}$ and ANDREA KLEINDIENST ${ }^{1,5}$
}

\author{
${ }^{1}$ Department of Neurosurgery, Klinikum St. Marien, D-92224 Amberg; ${ }^{2}$ Department of Neuropathology, \\ Regensburg University Hospital; ${ }^{3}$ Medical Sociology, Institute of Epidemiology and Preventative Medicine, \\ University of Regensburg, D-93053 Regensburg; ${ }^{4}$ Department of Radiology, Klinikum St. Marien, D-92224 Amberg; \\ ${ }^{5}$ Department of Neurosurgery, University of Erlangen-Nürnberg, D-91054 Erlangen, Germany
}

Received February 15, 2018; Accepted August 30, 2018

DOI: $10.3892 / \mathrm{ol} .2018 .9397$

\begin{abstract}
Despite progress in surgery and radiochemotherapy, the prognosis of glioblastoma $(\mathrm{GB})$ remains poor. GB cells exhibit a preference for hypoxia to maintain their tumor-forming capacity. Treatment strategies utilizing oxygen $\left(\mathrm{O}_{2}\right)$ or ozone $\left(\mathrm{O}_{3}\right)$ and generating reactive oxygen species induce cell growth inhibition and apoptosis. The anti-tumorigenic properties of $\mathrm{O}_{2}-\mathrm{O}_{3}$ are accompanied by a key role in regulating immunogenicity. The present study reported a case series of an intra-tumoral $\mathrm{O}_{2}-\mathrm{O}_{3}$ application in recurrent GB. Following surgery in combination with standard radiochemotherapy, $\mathrm{O}_{2}-\mathrm{O}_{3}(5 \mathrm{ml}$ at $40 \mu \mathrm{g} / \mathrm{ml})$ was applied every four weeks into the tumor vicinity. The patients received a median of 27 (range, 3-44) $\mathrm{O}_{2}-\mathrm{O}_{3}$ applications. In addition, a systematic literature search was performed in order to evaluate the role of $\mathrm{O}_{3}$ in the treatment of malignancies. The median overall survival rate was 40 (range, 16-53) months. The median survival rate following the first recurrence or the initiation of the $\mathrm{O}_{2}-\mathrm{O}_{3}$ treatment, respectively, was 34 (range, 12-53) months. In one patient, a local infection and in another, hemorrhage occurred, necessitating in both the temporary removal of the reservoir. The data from the present study support the potential benefit of an intra-tumoral $\mathrm{O}_{2}-\mathrm{O}_{3}$ application in recurrent GB. The scientific literature revealed by the bibliographic search suggests that $\mathrm{O}_{3}$ may be considered a viable adjuvant therapy in oncological patients. The present study may serve as a starting point for further observational and clinical studies elucidating the cellular and systemic effects of $\mathrm{O}_{2}$ and/or $\mathrm{O}_{3}$ and demonstrating their efficacy and safety in larger patient samples.
\end{abstract}

Correspondence to: Professor Andrea Kleindienst, Department of Neurosurgery, University Erlangen-Nürnberg, 6 Schwabachanlage, D-91054 Erlangen, Germany

E-mail: andrea.kleindienst@uk-erlangen.de

Key words: glioblastoma, ozone, oxygen, intra-tumoral treatment

\section{Introduction}

Despite significant advances in the basic understanding of tumor pathogenesis, improvement in surgical techniques and new adjunct treatment, the median overall survival rate of patients with glioblastoma (GB) has increased only by 3.3 months (from 11.3 to 14.6 months) until $2010(1,2)$ with a long-term survival rate above three years of only 3 to $5 \%$ (3). During the past decade, the consistent implementation of surgical re-resection in recurrent GB has helped to improve this devastating figure resulting in up to 25 months of overall survival rate, and 11.9 months following the first resection (4). The main predictive factors of survival are tumor localization in eloquent areas of the brain and the functional performance and tumor volume of the patient.

In GB, a small cell population with stem cell-like properties is resistant to chemotherapy. These cells exhibit unique energy metabolic characteristics (5), including low mitochondrial respiration and a preference for hypoxia, to maintain their tumor-forming capacity (6). In vitro, hypoxia promotes the survival of these clonogenic cancer stem cells (7) and inhibits their differentiation even if the cultures are returned to normoxic conditions (8). Furthermore, approximately half of all human GB respond to hypoxia by inducing c-Met, with subsequent enhancement of tumor cell migration and invasion (9).

Treatment strategies utilizing reactive oxygen $\left(\mathrm{O}_{2}\right)$ species induce cell death by autophagy and apoptosis in glioma cell cultures (10). Employing positron emission tomography (PET) or advanced magnetic resonance imaging (MRI) techniques such as MR spectroscopy enable the monitoring of local $\mathrm{O}_{2}$ levels (11). The intracellular in vivo oxymetry in rats implanted with the aggressive glioma cell line 9L demonstrates the preference for low tumor $\mathrm{pO}_{2}$ levels around $45 \mathrm{mmHg}$ (12). Treatment with bischloroethylnitrosourea (BCNU) resulted in an immediate and significant increase in $\mathrm{pO}_{2}$ up to $140 \mathrm{mmHg}$ (12). These anti-tumorigenic properties of oxygen are accompanied by its key role in regulating the immunogenicity of primary human glioma cells (13). Furthermore, the application of $\mathrm{O}_{2}$ plus ozone $\left(\mathrm{O}_{3}\right)$ in two different human neuroblastoma cell lines (SK-N-SH and SK-N-DZ) induced cell growth inhibition at $\mathrm{G}_{2}$ phase and cell cycle perturbation in both cell lines (14). 
Ozone is a gas that is produced endogenously by granulocytes. In the presence of an electron donor, reactive $\mathrm{O}_{2}$ species are produced, particularly hydrogen peroxide (15). Clinical $\mathrm{O}_{3}$ application has resulted in improved wound healing $(16,17)$, and the improvement of radiation-induced proctitis (18) and cystis (19), as well as the improvement of osteonecrosis (20-22). The toxicity of inhaled $\mathrm{O}_{3}$ can be reduced by applying the gas for a calculated period and at lower doses (23-25) although certain genetic variance in the $\mathrm{O}_{3}$ response exist (26). However, $\mathrm{O}_{3}$ acts antineoplastically in the presence of carcinogens if administered by inhalation (27,28), intra-vesicular (29) or intra-peritoneal $(30,31)$ instillation. Since $\mathrm{O}_{3}$ stimulates the release of immunoactive cytokines (32), these effects are more likely to be the result of an immune-mediated reaction rather than being a direct consequence of administration (33).

Studies have emphasized that $\mathrm{O}_{3}$ therapy can be considered a serious adjuvant therapy in oncological patients receiving radiochemotherapy (34). The present study reports data from the off-label application of $\mathrm{O}_{2}-\mathrm{O}_{3}$ into the tumor vicinity of GB following surgery in a limited series of patients. In addition, the results of a systematic literature search on $\mathrm{O}_{3}$ treatment following surgery for malignancies are presented.

\section{Materials and methods}

Between January 2012 and December 2013, patients diagnosed with GB at the Klinikum Amberg were offered an intra-tumoral treatment with $\mathrm{O}_{2}-\mathrm{O}_{3}$ extending the standard therapy as determined by the local tumor board. Following extensive information about their options and the possible side effects of the treatment, five patients provided their informed consent, and the ethical committee of the Bavarian National Medical Association approved the study, based on the Helsinki Declaration of 1964, revised 2013 (EK-Nr. 2013-125). Informed consent included publication of the case report and any accompanying images. Part of the illustrative case was presented as a poster on the Brain Tumor Meeting May 2013 in Berlin.

Treatment. Together with the re-resection in recurrent GB, a Rickham reservoir was implanted with the tip ending in the middle of the resection area. The exact catheter localization and the extent of tumor resection were confirmed by an early ( $<72$ h post-operatively) contrast-enhanced MRI. Subsequently, five $\mathrm{ml}$ of $\mathrm{O}_{2}-\mathrm{O}_{3}$ were applied monthly through the reservoir at a concentration of $40 \mu \mathrm{g} \mathrm{O}_{3}$ per ml.

The standard adjuvant therapy following the initial surgery for GB consisted of radiotherapy with a local boost and chemotherapy according to Stupp et al (2); $75 \mathrm{mg} / \mathrm{m}^{2}$ body surface temozolomide followed by cycles with $150 \mathrm{mg} / \mathrm{m}^{2}$ body surface, five days per week for the irradiation period, followed by a three week off/one week on schedule. Following progression or recurrence and re-section, the patients were switched to PCV chemotherapy (procarbacine $60 \mathrm{mg} / \mathrm{m}^{2}$ day 8 to 21 , CCNU $100 \mathrm{mg} / \mathrm{m}^{2}$ day and vincristine $1.4 \mathrm{mg} / \mathrm{m}^{2}$ day $8+29$ ).

Histological assessment. Tumor biopsies at primary resection and recurrence(s) were evaluated by an experienced neuropathologist and classified according to the criteria of the WHO 2007 classification of tumors of the central nervous system. Prior to publication, the histological results were reviewed and adapted to the current WHO classification of 2016 (35). The standard work-up for diagnostics comprised routine histological stains, immunohistochemistry, including the p53 (BP53-12) and Ki-67 (Mib-1) antigens, and molecular diagnostics for O-6-methylguanine-DNA-methyltransferase (MGMT) promoter methylation and isocitrate dehydrogenase (IDH) $1 / 2$ mutations. Additionally, immunohistochemistry for hypoxia-inducible factor (HIF)- $1 \alpha$ and HIF-2 $\alpha$ was performed for investigative purposes (Fig. 1). Immunohistochemistry on formalin-fixed and paraffin-embedded tissue samples was performed as described previously (36). In brief, 5-mm sections were cut and slides were deparaffinized and, following microwave antigen retrieval, stained using the EnVision+ Dual Link System-HRP (DAB+; K4065; Dako; Agilent Technologies $\mathrm{GmbH}$, Waldbronn, Germany) according to the manufacturer's protocol. Anti-HIF-1 $\alpha$ (NB100-123; Novus Biologicals, Ltd., Cambridge, UK) and anti HIF-2 $\alpha$ ha (NB100-122; Novus Biologicals, Ltd.) primary antibodies were used at 1:50 in phosphate buffered saline supplemented with $1 \%$ bovine serum albumin. Pre-treatment for antigen retrieval was not applied.

Magnetic resonance tumor volumetry. Volumetric analysis was performed on a GE Advantage Workstation (GE Healthcare Life Sciences, Little Chalfont, UK; version 4.7, Operation System 2.0 on a HELiOS 6.6.1 subsystem) by a radiologist. Tumor size and volume were calculated by semi-automated contouring of tumor borders on each T1 weighted-slice (post gadolinium) in $\mathrm{cm}^{3}$ and maximum $2 \mathrm{D}$ diameter in $\mathrm{mm}$, as outlined in Fig. 2. Slice thickness was 1 and $5 \mathrm{~mm}$, dependent on the subsequent protocols of MRI examination sequences applied between January 2012 and July 2017. Enhancing areas were considered as tumor with the exception of obvious vessels, artifacts or postoperative resection defects.

Statistical analysis. Dichotomous or categorical parameters are presented in frequencies and percentages. Metric variables are provided as median and range. Statistical analyses were performed using SPSS version 21 (IBM Corp., Armonk, NY, USA).

Systematic literature search. A systematic literature search was performed for observational and clinical studies utilizing an $\mathrm{O}_{3}$ treatment for malignancies. Studies published between $01 / 01 / 1987$ and 01/12/2017 were included, with no limitation regarding study type and sample unit (observational or experimental, animal or patient, in vitro or in vivo). The retrieval of studies was performed in PubMed using the combined filter and Medical Subject Headings (MeSH) term: ['Ozone/surgery' (Mesh) OR 'Ozone/therapeutic use' (Mesh) OR 'Ozone/therapy' (Mesh)) AND 'Neoplasms' (Mesh)] The records were screened based on title and abstract independently. Finally, the remaining records were evaluated by reading the full-text papers. All relevant characteristics (study type, disease, route of $\mathrm{O}_{3}$ application, unit of analysis, sample size and main findings) reported in the studies were extracted into an evidence table.

\section{Results}

The demographic and disease-related characteristics are summarized in Table I. The patient group comprised two 

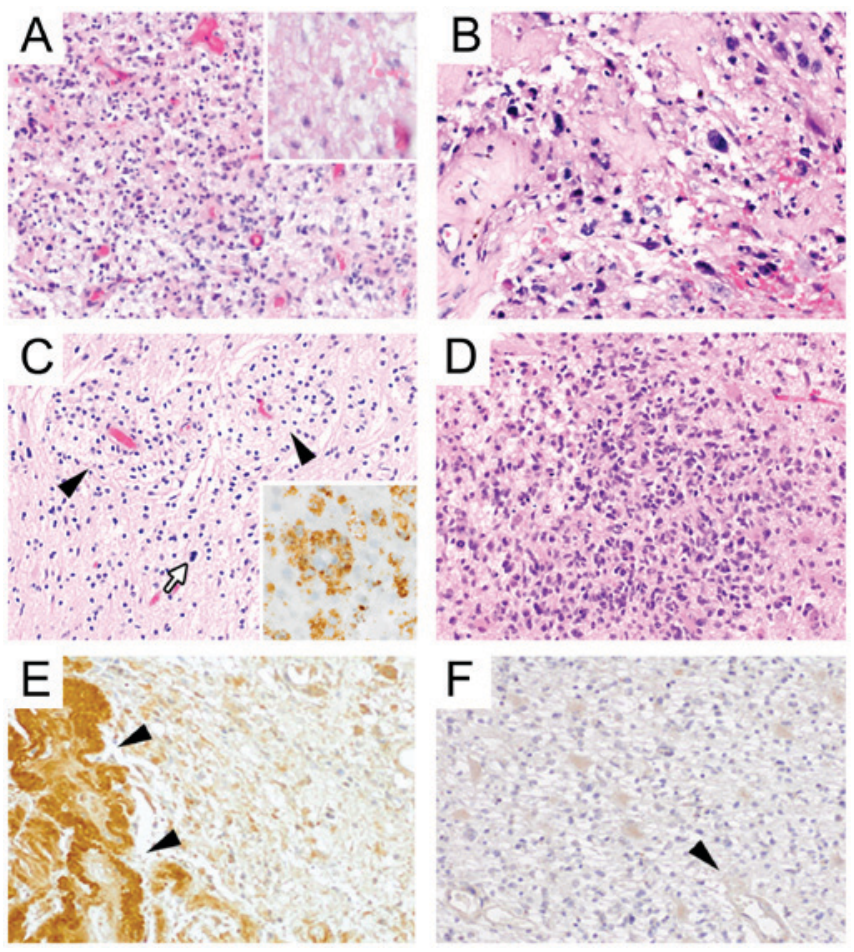

Figure 1. (A) The initial stereotactic biopsy showed a pleomorphic astrocytic tumor with focal necrosis (insert) corresponding to glioblastoma (WHO grade IV). (B) Also in the first recurrence (six months later) pleomorphic astrocytic tumor cells were present. Additionally, tumor vessels exhibited fibroid changes most likely as a therapy-induced alteration. (C) The first resection after application of $\mathrm{O}_{2}-\mathrm{O}_{3}$ showed CNS tissue with mainly reactive and resorptive changes. Note accumulation of macrophages (black arrowheads) that stain immunohistochemically for the CD68 (PGM1) antigen (insert). Only single scattered pleomorphic astrocytic (tumor) cells can be detected (white arrow). (D) Final resection about 31/4 years after the initia surgery presented with the histology of a full-blown cell-rich tumor recurrence. (E and F) HIF-2 $\alpha$ staining at different time points: Note that there is markedly higher HIF- $2 \alpha$ expression in the tissue from the first recurrence (prior to $\mathrm{O}_{2}-\mathrm{O}_{3}$ ) (E) than in the final resection immediately following $\mathrm{O}_{2}-\mathrm{O}_{3}$ treatment (F). HIF-2 $\alpha$ is particularly expressed in blood vessels prior to $\mathrm{O}_{2}-\mathrm{O}_{3}$ (black arrowheads). No differences between biopsies were observed for HIF-1 $\alpha$ immunostaining (data not shown). HIF, hypoxia-inducible factor.

women and three men with a median age of 48 years at diagnosis (range 31 to 68 years), the Karnofsky score (37) was $80 \%$ (range 50 to $90 \%$ ).

Primary treatment/initial surgery. In two patients the diagnosis was established following a biopsy, in two patients following a partial resection. In one patient the initial resection was complete and at her request the $\mathrm{O}_{2}-\mathrm{O}_{3}$ therapy was started following diagnosis.

In four out of five patients molecular neuropathology was $I D H$ wild-type GB; in the youngest patient the GB exhibited an $I D H$ mutation corresponding to (secondary) GB, IDH-mutant. The MGMT promoter methylation status ranged between $<3$ and $25 \%$. The median Ki67 proliferation index was $30 \%$ (range 20 to $40 \%$ ), and the median nuclear score for $\mathrm{p} 53$ positivity was $20 \%$ (range 0 to $75 \%$ ).

Of the five patients, four received a radiotherapy with a median of 49 Gy (range, 46 to $50 \mathrm{~Gy}$ ) accompanied by a local boost of $11 \mathrm{~Gy}$ (range, 10 to $14 \mathrm{~Gy}$ ). In all patients, the initial chemotherapy was started with temozolomide according to Stupp et al (2).

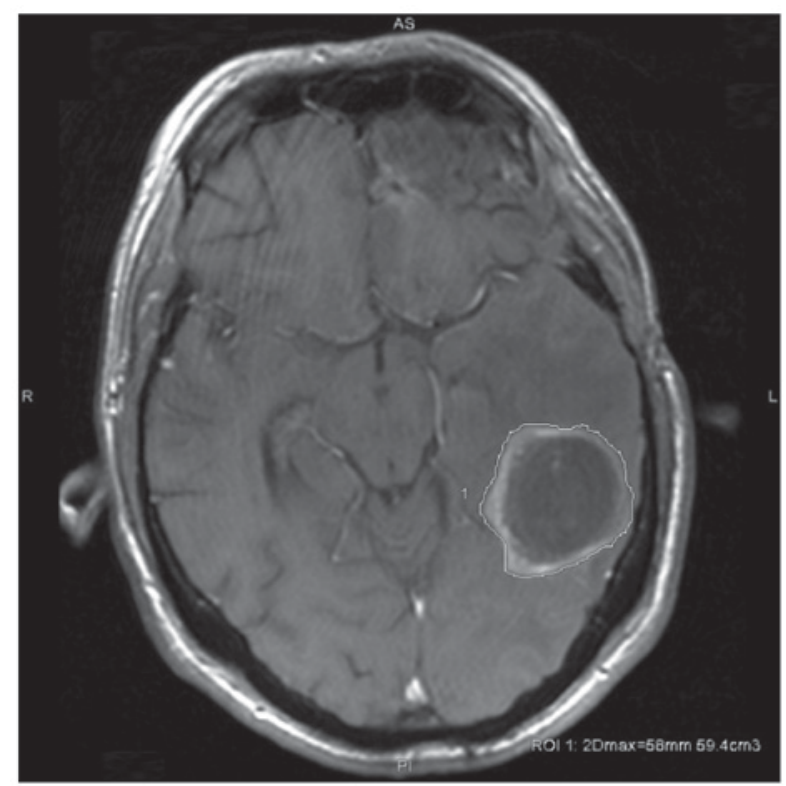

Figure 2. Tumor size was calculated by semi-automated contouring of tumor borders on each $\mathrm{T} 1$ weighted-slice (post gadolinium) in $\mathrm{cm}^{3}$, and additionally maximum $2 \mathrm{D}$ diameter in $\mathrm{mm}$.

Surgery for first recurrence/progression: Further treatment. The patient who insisted on receiving the $\mathrm{O}_{2}-\mathrm{O}_{3}$ treatment following the initial diagnosis remains in remission. In the other four patients, the first recurrence occurred in a median time of five months (range, 4 to 9 months). Together with the re-resection in recurrent $\mathrm{GB}$, a Rickham reservoir for $\mathrm{O}_{2}-\mathrm{O}_{3}$ application was implanted. Five milliliter of $\mathrm{O}_{2}-\mathrm{O}_{3}$ were applied monthly through the reservoir at a concentration of $40 \mu \mathrm{g} \mathrm{O}_{3}$ per $\mathrm{ml}$. The chemotherapy was changed in three out of four patients to $\mathrm{PCV}$; one patient refused further chemotherapy.

Overall survival and survival following initiation of ozone treatment. The patients received a median of 27 (range, 3 to 44$) \mathrm{O}_{2}-\mathrm{O}_{3}$ applications. The overall median survival rate was 40 months (range, 16 to 53 months). The median survival rate following the first recurrence subsequent to the initiation of the $\mathrm{O}_{2}-\mathrm{O}_{3}$ treatment was 34 months (range, 12 to 53 months). The progression-free survival rate was positively associated with a more extensive surgical re-resection $(\mathrm{P}=0.021)$, while the tumor volume was negatively correlated $(\mathrm{P}=0.027)$.

In one patient, a local infection occurred resulting in temporary removal of the reservoir. In another patient, a hemorrhage in the tumor vicinity around the catheter four months following the implantation necessitated the temporary removal of the reservoir. Based on a total of $115 \mathrm{O}_{2}-\mathrm{O}_{3}$ applications in five patients, the complication rate per application was $1.7 \%$.

Illustrative case. A 59-year-old male patient developed a seizure with a persisting hemiparesis. MRI demonstrated a contrast-enhancing lesion in the motor cortex $\left(10.5 \mathrm{~cm}^{3}\right.$; Fig. 3A). The histological examination confirmed a GB, IDH wild-type with a $\mathrm{Ki}-67$ proliferation rate of $20 \%$ and no relevant $M G M T$ promoter methylation (Fig. 1A). The patient was treated with radiochemotherapy (50 Gy with local boost of $10 \mathrm{~Gy}$ ), temozolomide at $75 \mathrm{mg} / \mathrm{m}^{2}$ body surface for four weeks, followed by one three weeks off and one cycle at $150 \mathrm{mg} / \mathrm{m}^{2}$. 


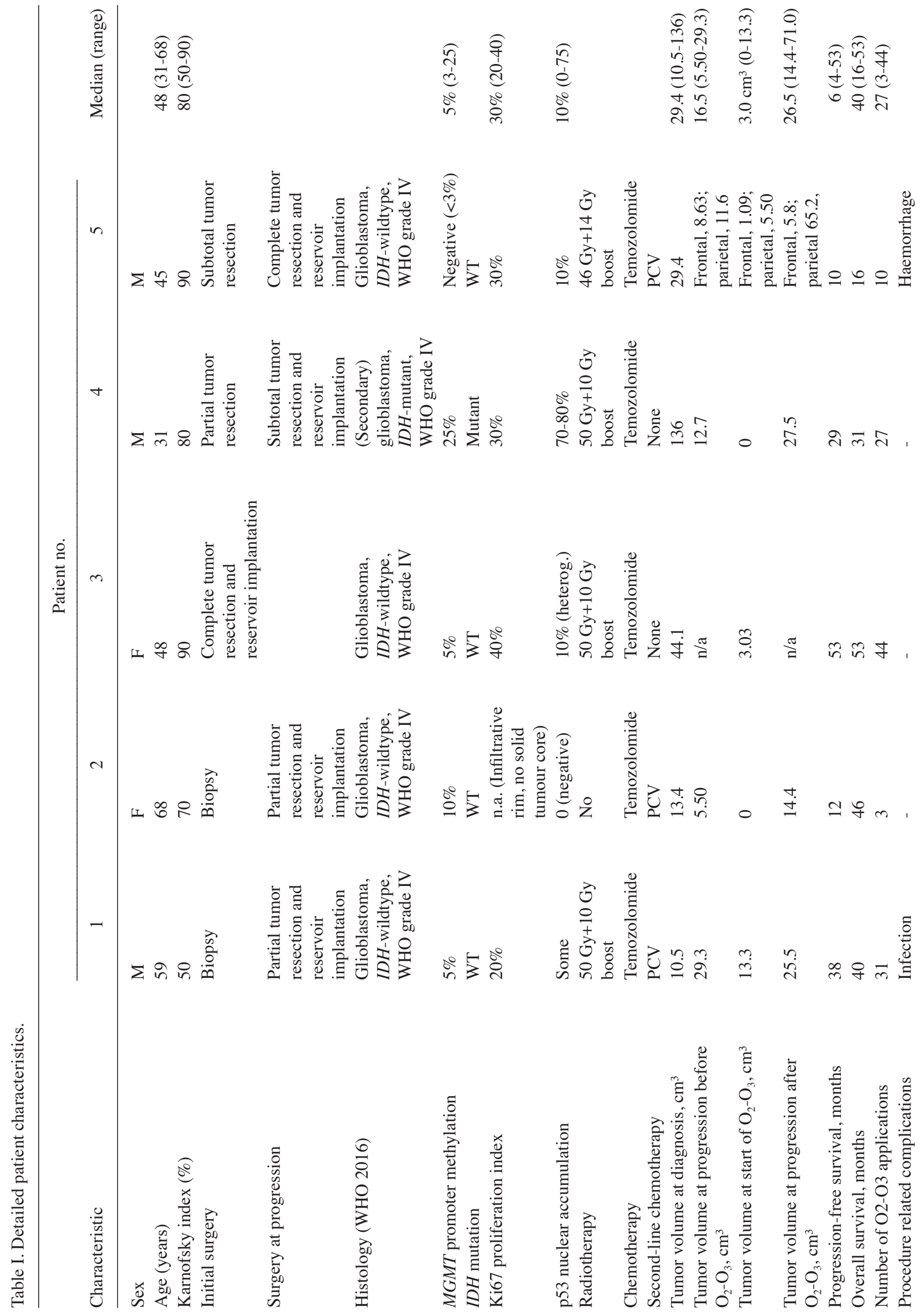




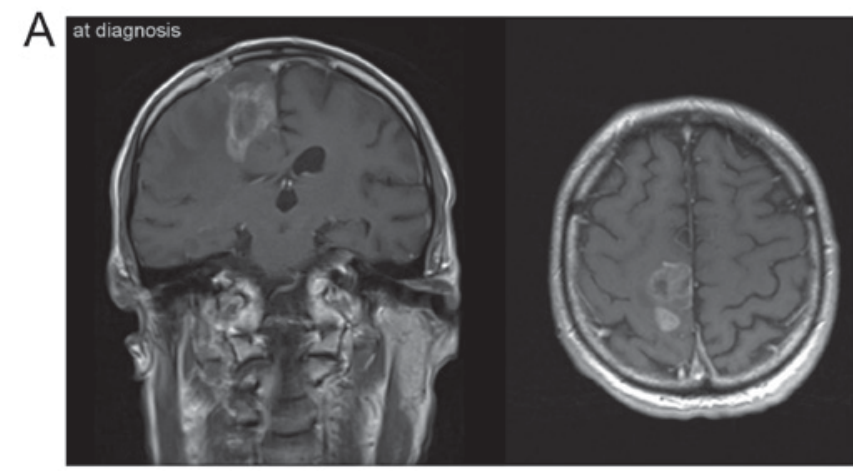

B

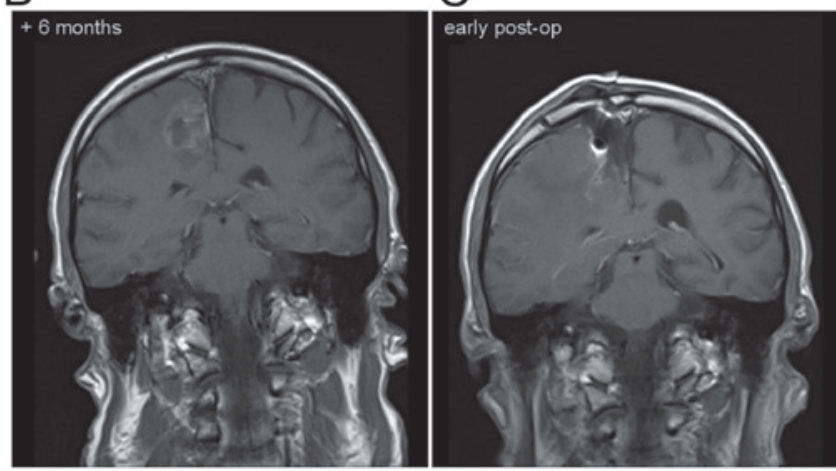

Figure 3. Sagittal and transverse MR T1-weighted images post gadolinium images of Patient No. 1 (illustrative case) at diagnosis (A), at progression six months after the initial biopsy and standard radio-chemotherapy (B), and following tumor resection and implantation of the reservoir for the intra-tumoral $\mathrm{O}_{2}-\mathrm{O}_{3}$ treatment (C).

The symptoms worsened and a tumor progression was evident at six months with a volume of $29.3 \mathrm{~cm}^{3}$ (Fig. 3B). At the time of tumor resection, a catheter connected to a reservoir was placed in the area of the former tumor cavity (Fig. 3C). Histology was performed and again demonstrated pleomorphic astrocytic tumor cells and fibroid changes of tumor vessels as a probable therapy-induced alteration (Fig. 1B). In addition, HIF-2 $\alpha$ staining could be observed (Fig. 1E). $\mathrm{O}_{2}-\mathrm{O}_{3}$ treatment was employed monthly together with a second-line PCV chemotherapy. Then, 13 months following surgery, the catheter was removed due to a local infection accompanied by seizures. The tissue demonstrated reactive and resorptive changes with an accumulation of macrophages (Fig. 1C). Next, six weeks later, the catheter was re-implanted and the intra-tumoral $\mathrm{O}_{2}-\mathrm{O}_{3}$ treatment was resumed together with the PCV chemotherapy. The patient returned to work and was in a stable neurological condition for almost 40 months. However, paresis of the arm worsened and MRI demonstrated tumor progression. A second re-section was performed, and presented with the histology of a full-blown cell-rich tumor recurrence (Fig. 1D) but with lowered HIF-2 $\alpha$ immunostaining (Fig. 1F) compared with the first recurrence and the situation prior to $\mathrm{O}_{2}-\mathrm{O}_{3}$ treatment. Comparing the two time points, no differences could be observed in HIF-1 $\alpha$ staining. The patient died 40 months after the initial diagnosis, and 33 months following the initiation of $\mathrm{O}_{2}-\mathrm{O}_{3}$ treatment. Another illustrative case is depicted in Fig. 4. This patient is still alive, more than 4 years after the diagnosis GB.

Findings from the literature search. The systematic literature search revealed 79 scientific studies. Following the screening 

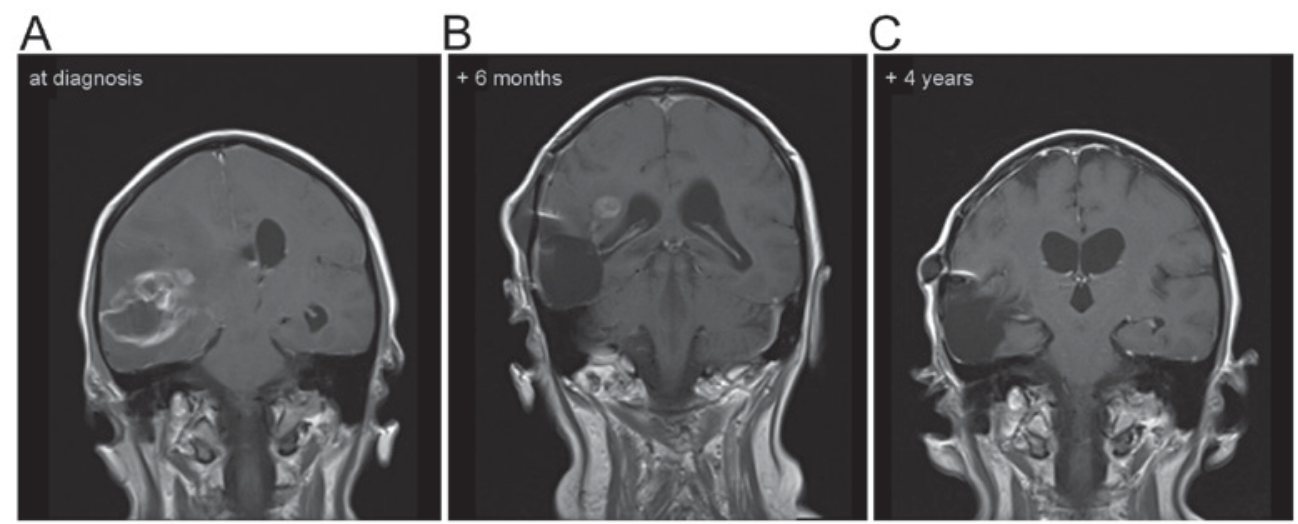

Figure 4. Sagittal MR T1-weighted images post gadolinium images of Patient No. 3 in whom the $\mathrm{O}_{2}$ - $\mathrm{O}_{3}$ treatment was started following the initial surgery and diagnosis of (A) GB. Six months later, some contrast enhancement was still visible (B), that was not apparent four years following diagnosis (C).

of titles and abstracts, 20 articles fulfilled the criteria for eligibility. In three cases, no English full-text articles were available. Finally, a total of seven clinical and ten basic research studies met the eligibility criteria applied to the studies. Data extracted from these studies are shown in Table II.

All cohorts/samples were independent and no overlap of included individuals could be identified. Overall, the sample sizes of the clinical studies detected by the literature search ranged from case reports to a prospective phase I-II study including one to 24 patients. The basic research studies adopted the guidelines for the care and use of animals and included 20 to more than 100 animals.

\section{Discussion}

The rationale to perform an individual off-label treatment in GB patients was three-fold: There was i) in vitro and in vivo evidence for a preference for hypoxia in GB, ii) in vitro and in vivo evidence for the treatment efficacy of hyperoxia generating reactive $\mathrm{O}_{2}$ species in $\mathrm{GB}$, and iii) in vivo evidence for the treatment effect of $\mathrm{O}_{3}$ in stimulating the immune system in other types of cancer $(31,33)$.

Tumor cells, particularly those with stem cell-like properties, exhibit a preference for hypoxia $(6,12)$. Therefore the intra-tumoral application of $\mathrm{O}_{2}$ was aimed at establishing normoxia, thereby inhibiting proliferation and migration (9) in addition to promoting differentiation $(5,8)$. Whether this target was accomplished, was not verified. Five $\mathrm{ml}$ of $\mathrm{O}_{2}-\mathrm{O}_{3}$ were applied intra-tumorally at a concentration of $40 \mu \mathrm{g}$ ozone per ml once per month. While direct intracellular oxymetry can be utilized in basic research models, the measurement of tissue $\mathrm{O}_{2}$ levels in the clinical setting is restricted to advanced and not readily available techniques such as PET or MR spectroscopy (11).

HIFs are transcription factors that respond to decreases in available $\mathrm{O}_{2}$ in the cellular environment, or hypoxia. HIF-1 consists of an $\mathrm{O}_{2}$-sensitive $\alpha$-subunit and a constitutively expressed $\beta$-subunit, and belongs to a family of transcription factors [PER/aryl hydrocarbon receptor nuclear translocator (ARNT)/single minded (SIM)] (38-40). HIF-1 $\alpha$ facilitates, together with HIF- $2 \alpha, \mathrm{O}_{2}$ delivery and cellular adaptation to hypoxia by stimulating multiple biological processes, including erythropoesis, angiogenesis and anaerobic glucose metabo$\operatorname{lism}(41)$.
Histologically, following the intra-tumoral $\mathrm{O}_{2}-\mathrm{O}_{3}$ application mainly reactive and resorptive changes were identified (Fig. 1C). Notably, while relevant HIF-1 $\alpha$ staining was not present prior to or following the intra-tumoral $\mathrm{O}_{2}-\mathrm{O}_{3}$ application, the HIF-2 $\alpha$ expression (particularly in tumor blood vessels) was higher under the hypoxic conditions prior to, compared with following, the treatment (Fig. 1E and F).

Treatment strategies utilizing reactive $\mathrm{O}_{2}$ species in glioma cell cultures have been demonstrated to induce cell death by autophagy and apoptosis (10) or at least cell growth inhibition (14). Histologically, the present illustrative case identified mainly reactive and resorptive changes following the intra-tumoral $\mathrm{O}_{2}-\mathrm{O}_{3}$ application for a long time period. Only single scattered pleomorphic astrocytic tumor cells could be detected (Fig. 1C).

$\mathrm{O}_{3}$, a gas that is produced endogenously by granulocytes, induces the generation of reactive $\mathrm{O}_{2}$ species, stimulates the release of immunoactive cytokines (12) and regulates immunogenicity of human glioma cells (13). The intra-peritoneal insufflation of $\mathrm{O}_{2}-\mathrm{O}_{3}$ resulted in a tumoricidal immune response in experimental head and neck squamous carcinoma (32) with subsequent complete tumor remission (31). Oxidative stress converts the immune response from a tumor permissive to a tumoricidal one, probably through the stimulation of systemic T cells, resident macrophages and dendritic cells (32).

Human natural killer cells as part of a systemic immune response are most likely at least in part, responsible for the absence of metastases in GB patients (42). The exposure of peripheral blood mononuclear cells to a single dose of $1 \mu \mathrm{g} / \mathrm{ml} \mathrm{O}_{3}$ increased the numbers of CD3-CD16+/56+ natural killer cells in vitro (43). In human GB tissue of long-term (>36 months) survivors, the number of CD 8, CD 20, CD 25 and CD 95 positive lymphocytes was significantly increased compared with short-term $(<1$ year) survivors. Therefore, the $\mathrm{O}_{2}-\mathrm{O}_{3}$ application in GB may act as an immunotherapy through the enhancement of human natural killer cells. Histologically, in this context an accumulation of macrophages was identified that immunohistochemically stained for the CD68 (PGM1) antigen following the intra-tumoral $\mathrm{O}_{2}-\mathrm{O}_{3}$ application in our illustrative case (Fig. 1C).

The intra-peritoneal application of $1 \mathrm{mlO}_{3}$ at 20 or $40 \mu \mathrm{g} / \mathrm{ml}$ into the peritoneal cavity of mice has been performed without side effects in a control group confirming thereby the safety 


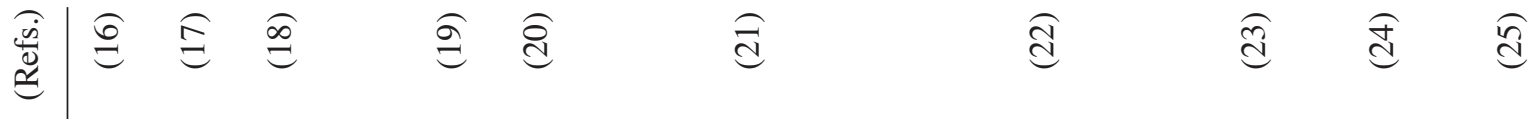

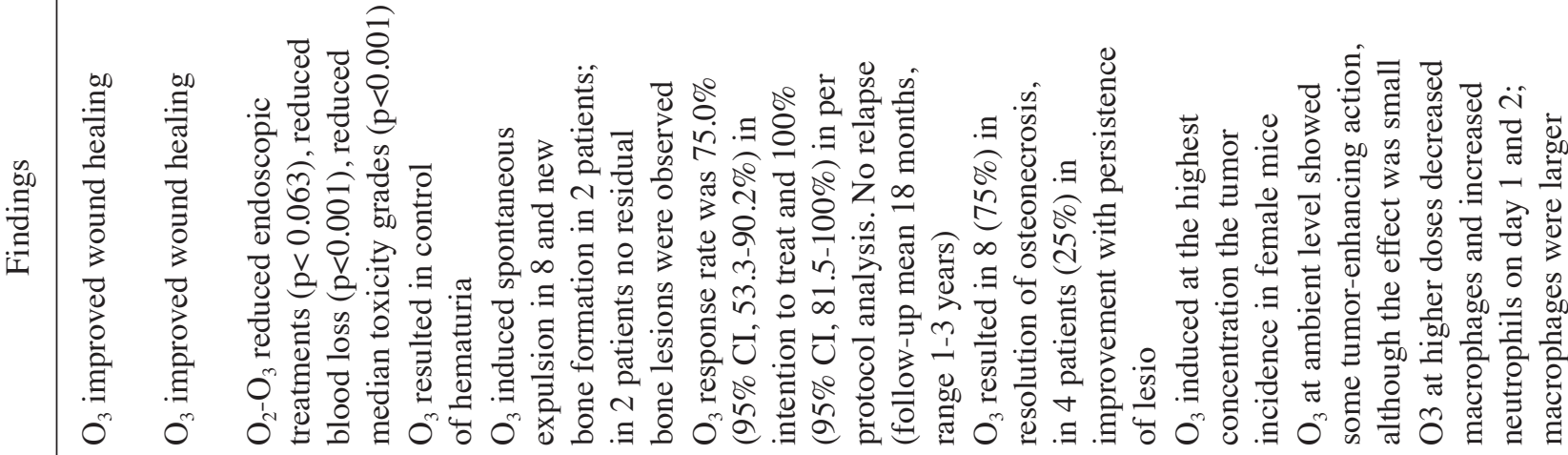

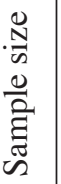

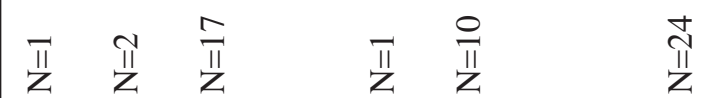

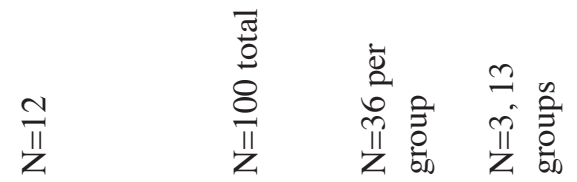

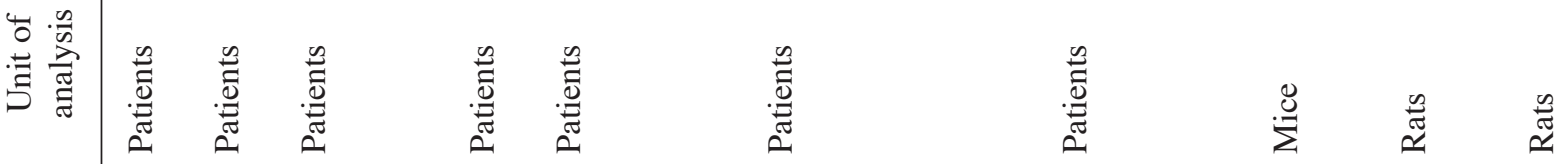

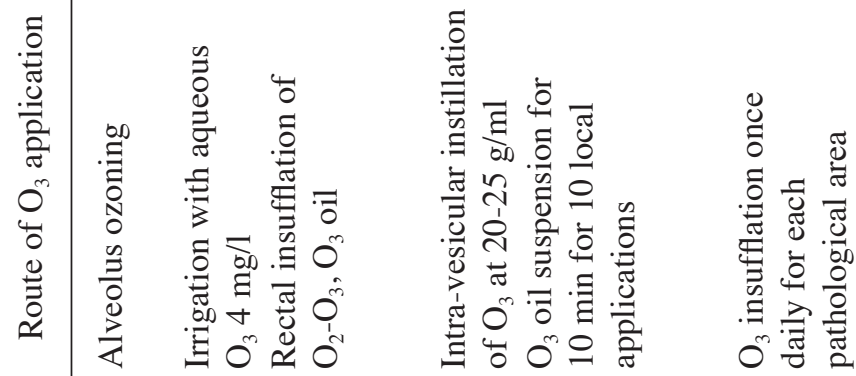

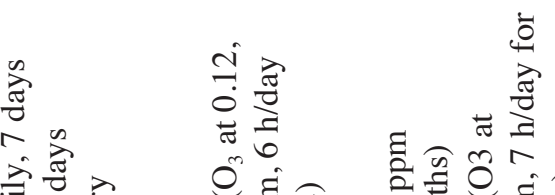

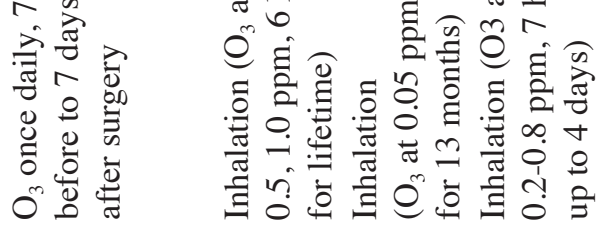

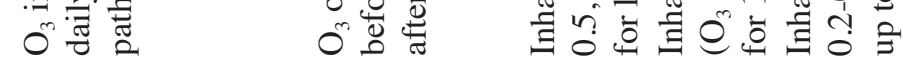

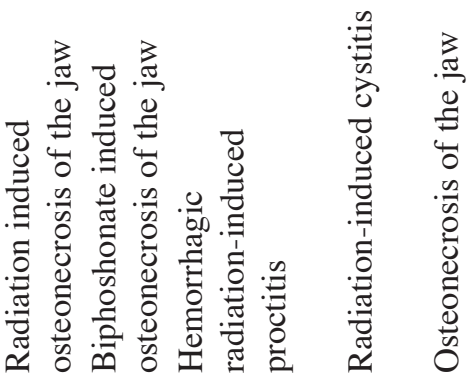

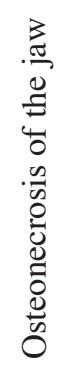

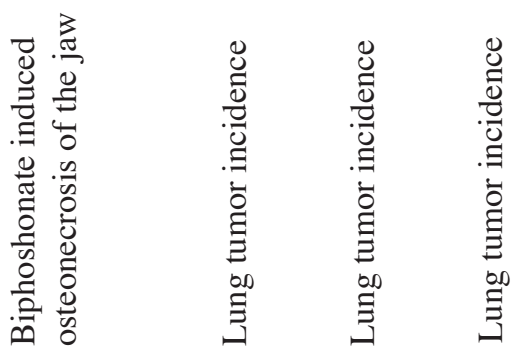

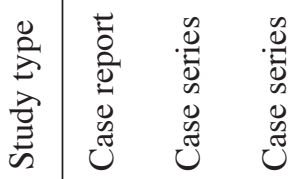

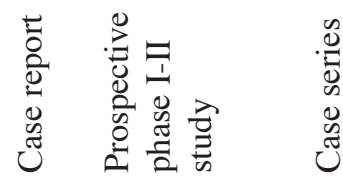

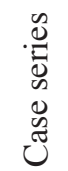

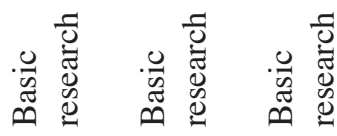

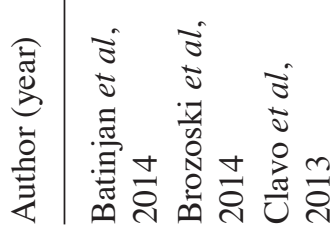

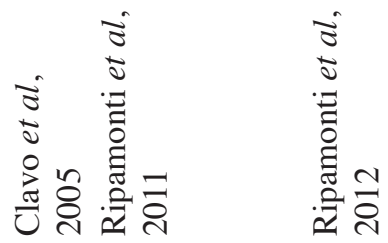

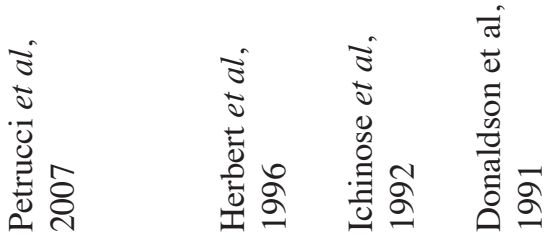




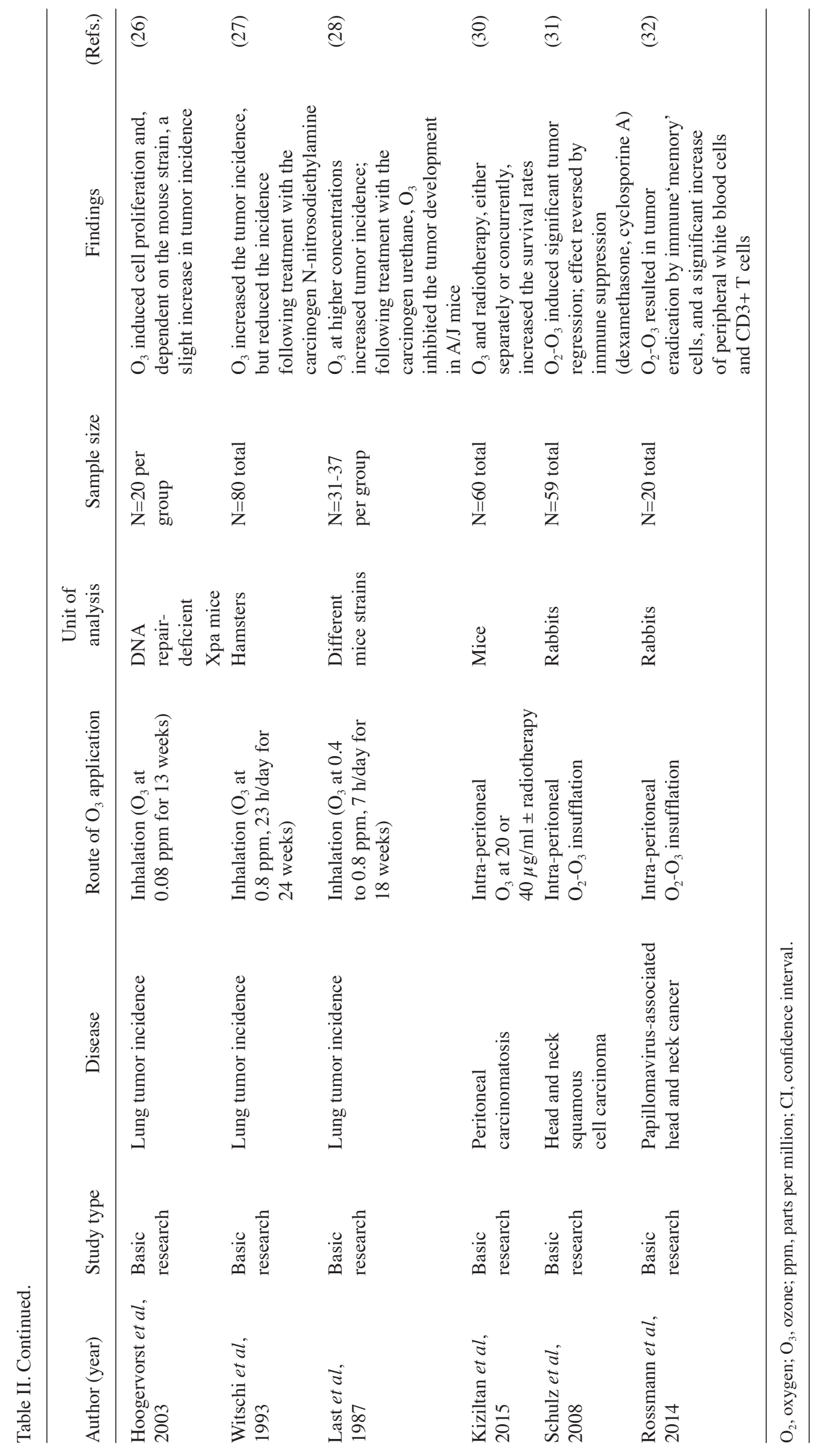


of the selected concentration (30). Andreula et al (44) safely injected four $\mathrm{ml} \mathrm{O}_{3}$ at $27 \mu \mathrm{g} / \mathrm{ml}$ into the lumbar disc and periganglionic in 600 patients with clinical signs of lumbar disk nerve root compression. The present study applied five $\mathrm{ml} \mathrm{O}_{3}$ at $40 \mu \mathrm{g} / \mathrm{ml}$ into the tumor cavity and could not identify any direct cell damage or necrosis around the cavity histologically. Nevertheless, the safety of this application has to be confirmed by cell culture of normal CNS tissue and glioma cells in addition to in vivo studies.

The median overall survival rate in our series comprising of five patients was 40 months. Since in one patient the $\mathrm{O}_{2}-\mathrm{O}_{3}$ treatment was started following diagnosis, the median survival following recurrence was 30.5 months (range, 12 to 37 months) in the remaining four patients. These data outperform previously published data (3) and the data from a recent multicenter trial including 505 patients from 20 institutions undergoing re-resection in recurrent GB (4). In that multicenter study, the median overall survival rate was 25 months and 11.9 months following the first resection. Furthermore, one of the patients in the present study treated with local $\mathrm{O}_{2}-\mathrm{O}_{3}$ in addition to the standard treatment following initial surgery remains alive, 53 months following the diagnosis of GB (Fig. 4A-C). The patients in our series did not differ substantially with regard to known prognostic factors: The median age at diagnosis was 48 years (range, 31 to 68 years), the median Karnofsky score at presentation $80 \%$ (range, 50 to $90 \%$ ), the median proliferation index $30 \%$ (range, 20 to $40 \%$ ) and the median quantitative $M G M T$ promoter methylation was $5 \%$ (range, 3 to $25 \%$ ).

However, the authors are aware that a study focusing on long-term survivors following GB presented even better data (45). That study retrospectively identified 50 long-term GB survivors ( $>36$ months). In this selected cohort, the median progression-free survival rate was 25.4 months (range, 2.3 to 97.8 months) compared with six months (range, 4 to 52 months) in our series, and the overall survival rate of long-term survivors was 55.9 months (range, 38.2 to 98.6 months) compared with 40 months (range, 16 to 52 months) in our series.

The authors are aware of several limitations of the present study. The exact dose and the timing of the application were based on estimates and patient comfort. Optimization of both should be performed either in a basic research setting utilizing tissue oxymetry or mapping brain tissue $\mathrm{O}_{2}$ saturation in the clinical setting with PET or MRI. Furthermore, this off-label case series should be transferred into a clinical trial.

Taken together, the overall survival rate of our patient series is longer than obtained in an unselected multicenter study. Taking a closer look at a long-term GB survivor cohort (44), both progression-free survival and overall survival rate are slightly shorter. These results and the existing evidence revealed by the systematic literature search highlighted that $\mathrm{O}_{3}$ therapy could be considered a viable adjuvant therapy in oncological patients receiving radiochemotherapy (34). The case series of the present study indicated the potential benefit and efficacy of intra-tumoral $\mathrm{O}_{2}-\mathrm{O}_{3}$ application following surgery for GB. Following this descriptive approach, further observational and experimental research is warranted to elucidate cellular and systemic effects, in addition to ensuring safety by applying inference statistical analyses based on an appropriate sample size.

\section{Acknowledgements}

Part of the illustrative case was presented as a poster on the Brain Tumor Meeting May 2013 in Berlin (abstract no. 36).

\section{Funding}

No funding was received.

\section{Availability of data and materials}

The datasets generated and/or analyzed during the current study are available from the corresponding author on reasonable request.

\section{Authors' contributions}

RM designed the study. MJR performed the histological examination and contributed to the drafting and revision of the manuscript. FDS performed the literature search, data analysis and interpretation and contributed to writing the manuscript. MF analyzed and interpreted the radiological patient data. AK revised the study design, structured the data aquisition, analysed and interpreted the data and drafted the manuscript. All authors read and approved the final manuscript.

\section{Ethics approval and consent to participate}

The present study was approved by the ethical committee of the Bavarian National Medical Association (approval no. EK-Nr. 2013-125). All patients provided written informed consent.

\section{Patient consent for publication}

Following extensive information about their options and the possible side effects of the treatment, all patients provided their informed consent, including the publication of the case report and any accompanying images.

\section{Competing interests}

The authors declare that they have no competing interests.

\section{References}

1. Park JK, Hodges T, Arko L, Shen M, Dello Iacono D, McNabb A, Olsen Bailey N, Kreisl TN, Iwamoto FM, Sul J, et al: Scale to predict survival after surgery for recurrent glioblastoma multiforme. J Clin Oncol 28: 3838-3843, 2010.

2. Stupp R, Hegi ME, Mason WP, van den Bent MJ, Taphoorn MJ, Janzer RC, Ludwin SK, Allgeier A, Fisher B, Belanger K, et al: Effects of radiotherapy with concomitant and adjuvant temozolomide versus radiotherapy alone on survival in glioblastoma in a randomised phase III study: 5-year analysis of the EORTC-NCIC trial. Lancet Oncol 10: 459-466, 2009.

3. Krex D, Klink B, Hartmann C, von Deimling A, Pietsch T, Simon M, Sabel M, Steinbach JP, Heese O, Reifenberger G, et al: Long-term survival with glioblastoma multiforme. Brain 130: 2596-2606, 2007.

4. Ringel F, Pape H, Sabel M, Krex D, Bock HC, Misch M, Weyerbrock A, Westermaier T, Senft C, Schucht P, et al: Clinical benefit from resection of recurrent glioblastomas: Results of a multicenter study including 503 patients with recurrent glioblastomas undergoing surgical resection. Neuro Oncol 18: 96-104, 2016. 
5. Kathagen A, Schulte A, Balcke G, Phillips HS, Martens T, Matschke J, Günther HS, Soriano R, Modrusan Z, Sandmann T, et al: Hypoxia and oxygenation induce a metabolic switch between pentose phosphate pathway and glycolysis in glioma stem-like cells. Acta Neuropathol 126: 763-780, 2013.

6. Seidel S, Garvalov BK, Wirta V, von Stechow L, Schänzer A, Meletis K, Wolter M, Sommerlad D, Henze AT, Nistér M, et al: A hypoxic niche regulates glioblastoma stem cells through hypoxia inducible factor 2 alpha. Brain 133: 983-995, 2010

7. Zhou Y, Zhou Y, Shingu T, Feng L, Chen Z, Ogasawara M, Keating MJ, Kondo S and Huang P: Metabolic alterations in highly tumorigenic glioblastoma cells: Preference for hypoxia and high dependency on glycolysis. J Biol Chem 286 32843-32853, 2011.

8. Bar EE, Lin A, Mahairaki V, Matsui W and Eberhart CG: Hypoxia increases the expression of stem-cell markers and promotes clonogenicity in glioblastoma neurospheres. Am J Pathol 177: 1491-1502, 2010.

9. Eckerich C, Zapf S, Fillbrandt R, Loges S, Westphal M and Lamszus K: Hypoxia can induce c-Met expression in glioma cells and enhance SF/HGF-induced cell migration. Int J Cancer 121 276-283, 2007

10. Trejo-Solis C, Jimenez-Farfan D, Rodriguez-Enriquez S, Fernandez-Valverde F, Cruz-Salgado A, Ruiz-Azuara L and Sotelo J: Copper compound induces autophagy and apoptosis of glioma cells by reactive oxygen species and JNK activation. BMC Cancer 12: 156, 2012

11. Mendichovszky I and Jackson A: Imaging hypoxia in gliomas. Br J Radiol 84: S145-S158, 2011

12. Kadayakkara DK, Janjic JM, Pusateri LK, Young WB and Ahrens ET: In vivo observation of intracellular oximetry in perfluorocarbon-labeled glioma cells and chemotherapeutic response in the CNS using fluorine-19 MRI. Magn Reson Med 64: 1252-1259, 2010

13. Olin MR, Andersen BM, Litterman AJ, Grogan PT, Sarver AL, Robertson PT, Liang X, Chen W, Parney IF, Hunt MA, et al: Oxygen is a master regulator of the immunogenicity of primary human glioma cells. Cancer Res 71: 6583-6589, 2011.

14. Cannizzaro A, Verga Falzacappa CV, Martinelli M, Misiti S, Brunetti $\mathrm{E}$ and Bucci $\mathrm{B}$ : $\mathrm{O}(2 / 3)$ exposure inhibits cell progression affecting cyclin B1/cdk1 activity in SK-N-SH while induces apoptosis in SK-N-DZ neuroblastoma cells. J Cell Physiol 213: 115-125, 2007.

15. Bocci VA: Scientific and medical aspects of ozone therapy. State of the art. Arch Med Res 37: 425-435, 2006.

16. Batinjan G, Filipovic Zore I, Vuletic M and Rupic I: The use of ozone in the prevention of osteoradionecrosis of the jaw. Saudi Med J 35: 1260-1263, 2014.

17. Brozoski MA, Lemos CA, Da Graca Naclério-Homem M and Deboni MC: Adjuvant aqueous ozone in the treatment of bisphosphonate induced necrosis of the jaws: report of two cases and long-term follow-up. Minerva Stomatol 63: 35-41, 2014.

18. Clavo B, Ceballos D, Gutierrez D, Rovira G, Suarez G, Lopez L, Pinar B, Cabezon A, Morales V, Oliva E, et al: Long-term control of refractory hemorrhagic radiation proctitis with ozone therapy. J Pain Symptom Manage 46: 106-112, 2013.

19. Clavo B, Gutiérrez D, Martín D, Suárez G, Hernández MA and Robaina F: Intravesical ozone therapy for progressive radiation-induced hematuria. J Altern Complement Med 11: 539-541, 2005.

20. Ripamonti CI, Cislaghi E, Mariani L and Maniezzo M: Efficacy and safety of medical ozone $(\mathrm{O}(3))$ delivered in oil suspension applications for the treatment of osteonecrosis of the jaw in patients with bone metastases treated with bisphosphonates: Preliminary results of a phase I-II study. Oral Oncol 47: 185-190, 2011.

21. Ripamonti CI, Maniezzo M, Boldini S, Pessi MA, Mariani L and Cislaghi E: Efficacy and tolerability of medical ozone gas insufflations in patients with osteonecrosis of the jaw treated with bisphosphonates-Preliminary data: Medical ozone gas insufflation in treating ONJ lesions. J Bone Oncol 1: 81-87, 2012.

22. Petrucci MT, Gallucci C, Agrillo A, Mustazza MC and Foà R: Role of ozone therapy in the treatment of osteonecrosis of the jaws in multiple myeloma patients. Haematologica 92: 1289-1290, 2007.

23. Herbert RA, Hailey JR, Grumbein S, Chou BJ, Sills RC, Haseman JK, Goehl T, Miller RA, Roycroft JH and Boorman GA: Two-year and lifetime toxicity and carcinogenicity studies of ozone in B6C3F1 mice. Toxicol Pathol 24: 539-548, 1996.

24. Ichinose T and Sagai M: Combined exposure to NO2, O3 and $\mathrm{H} 2 \mathrm{SO} 4-$ aerosol and lung tumor formation in rats. Toxicology 74 : 173-184, 1992.
25. Donaldson K, Brown GM, Brown DM, Slight J, Maclaren WM and Davis JM: Leukocyte-mediated epithelial injury in ozone-exposed rat lung. Res Rep Health Eff Inst: 1-27, 1991.

26. Hoogervorst EM, de Vries A, Beems RB, van Oostrom CT, Wester PW, Vos JG, Bruins W, Roodbergen M, Cassee FR, Vijg J, et al: Combined oral benzo[a]pyrene and inhalatory ozone exposure have no effect on lung tumor development in DNA repair-deficient Xpa mice. Carcinogenesis 24: 613-619, 2003.

27. Witschi H, Wilson DW and Plopper CG: Modulation of N-nitrosodiethylamine-induced hamster lung tumors by ozone. Toxicology 77: 193-202, 1993.

28. Last JA, Warren DL, Pecquet-Goad E and Witschi H: Modification by ozone of lung tumor development in mice. J Natl Cancer Inst 78: 149-154, 1987.

29. Teke K, Ozkan TA, Cebeci OO, Yilmaz H, Keles ME, Ozkan L, Dillioglugil MO, Yildiz DK and Dillioglugil O: Preventive effect of intravesical ozone supplementation on n-methyl-nnitrosourea-induced non-muscle invasive bladder cancer in male rats. Exp Anim 66: 191-198, 2017.

30. Kiziltan HȘ, Bayir AG, Yucesan G, Eris AH, İdin K, Karatoprak C, Aydin T, Akcakaya A and Mayadagli A: Medical ozone and radiotherapy in a peritoneal, Erlich-ascites, tumor-cell model. Altern Ther Health Med 21: 24-29, 2015.

31. Schulz S, Haussler U, Mandic R, Heverhagen JT, Neubauer A, Dünne AA, Werner JA, Weihe E and Bette M: Treatment with ozone/oxygen-pneumoperitoneum results in complete remission of rabbit squamous cell carcinomas. Int J Cancer 122:2360-2367,2008.

32. Rossmann A, Mandic R, Heinis J, Höffken H, Küssner O, Kinscherf R, Weihe E and Bette M: Intraperitoneal oxidative stress in rabbits with papillomavirus-associated head and neck cancer induces tumoricidal immune response that is adoptively transferable. Clin Cancer Res 20: 4289-4301, 2014

33. Bocci V: Does ozone really 'cure' cancer? Int J Cancer 123: 1222,2008

34. Luongo M, Brigida AL, Mascolo L and Gaudino G: Possible therapeutic effects of ozone mixture on hypoxia in tumor development. Anticancer Res 37: 425-435, 2017.

35. Louis DN, Perry A, Reifenberger G, von Deimling A, Figarella-Branger D, Cavenee WK, Ohgaki H, Wiestler OD, Kleihues P and Ellison DW: The 2016 World Health Organization Classification of tumors of the central nervous system: A summary. Acta Neuropathol 131: 803-820, 2016.

36. Delic S, Lottmann N, Jetschke K, Reifenberger $G$ and Riemenschneider MJ: Identification and functional validation of CDH11, PCSK6 and SH3GL3 as novel glioma invasion-associated candidate genes. Neuropathol Appl Neurobiol 38: 201-212, 2012.

37. Karnofsky DA: The bases for cancer chemotherapy. Stanford Med Bull 6: 257-269, 1948.

38. Kewley RJ, Whitelaw ML and Chapman-Smith A: The mammalian basic helix-loop-helix/PAS family of transcriptional regulators. Int J Biochem Cell Biol 36: 189-204, 2004

39. Semenza GL: Regulation of mammalian O2 homeostasis by hypoxia-inducible factor 1 . Annu Rev Cell Dev Biol 15: 551-578, 1999.

40. Wenger RH, Stiehl DP and Camenisch G: Integration of oxygen signaling at the consensus HRE. Sci STKE 2005: re12, 2005.

41. Semenza GL: HIF-1 and mechanisms of hypoxia sensing. Curr Opin Cell Biol 13: 167-171, 2001.

42. Lee SJ, Song L, Yang MC, Mao CP, Yang B, Yang A, Jeang J, Peng S, Wu TC and Hung CF: Local administration of granulocyte macrophage colony-stimulating factor induces local accumulation of dendritic cells and antigen-specific CD8+ T cells and enhances dendritic cell cross-presentation. Vaccine 33: 1549-1555, 2015

43. Kucuksezer UC, Zekiroglu E, Kasapoglu P, Adin-Cinar S, Aktas-Cetin E and Deniz G: A stimulatory role of ozone exposure on human natural killer cells. Immunol Invest 43: 1-12, 2014

44. Andreula CF, Simonetti L, De Santis F, Agati R, Ricci R and Leonardi M: Minimally invasive oxygen-ozone therapy for lumbar disk herniation. AJNR Am J Neuroradiol 24: 996-1000, 2003.

45. Adeberg S, Bostel T, König L, Welzel T, Debus J and Combs SE: A comparison of long-term survivors and short-term survivors with glioblastoma, subventricular zone involvement: A predictive factor for survival? Radiat Oncol 9: 95, 2014.

This work is licensed under a Creative Commons Attribution-NonCommercial-NoDerivatives 4.0 International (CC BY-NC-ND 4.0) License. 